University of Massachusetts Amherst

ScholarWorks@UMass Amherst

Chemistry Department Faculty Publication Series

Chemistry

1990

\title{
Use of Masking Agents in the Determination of Lead in Tap Water by Flame Atomic Absorption Spectrometry With Flow Injection Pre- concentration
}

\author{
S. R. Bysouth \\ Loughborough University of Technology \\ Julian Tyson \\ University of Massachusetts Amherst \\ Peter B. Stockwell
}

Follow this and additional works at: https://scholarworks.umass.edu/chem_faculty_pubs

Part of the Analytical Chemistry Commons

\section{Recommended Citation}

Bysouth, S. R.; Tyson, Julian; and Stockwell, Peter B., "Use of Masking Agents in the Determination of Lead in Tap Water by Flame Atomic Absorption Spectrometry With Flow Injection Pre-concentration" (1990). Analyst. 1405.

Retrieved from https://scholarworks.umass.edu/chem_faculty_pubs/1405 


\title{
Use of Masking Agents in the Determination of Lead in Tap Water by Flame Atomic Absorption Spectrometry With Flow Injection Pre-concentration*
}

\author{
Stephen R. Bysoutht and Julian F. Tysont \\ Department of Chemistry, University of Technology, Loughborough, Leicestershire LE11 3TU, UK \\ Peter B. Stockwell \\ PS Analytical Ltd., Unit B4, Chaucer Business Park, Watery Lane, Kemsing, Sevenoaks, Kent TN156QY, \\ UK
}

\begin{abstract}
The selectivity of immobilised 8-hydroxyquinoline for lead is shown to be improved by the use of masking agents during pre-concentration, prior to determination by flame atomic absorption spectrometry. Interference by iron, copper, aluminium and zinc is suppressed by including triethanolamine, thiourea, fluoride, acetylacetone or cyanide in the buffer as masking agents. Species such as iron or copper can completely prevent the pre-concentration of lead. This is shown to be overcome by using a buffer consisting of $0.2 \mathrm{M}$ boric acid, $2 \%$ triethanolamine, $2 \%$ thiourea and $2 \%$ acetylacetone, even when the interfering species is in a 200 -fold excess over lead. Recoveries from tap water samples, to which various amounts of lead had been added, ranged from 94 to $108 \%$. Results of analyses of tap water samples using this method were in good agreement with those obtained by electrothermal atomic absorption spectrometry.
\end{abstract}

Keywords: Lead pre-concentration; flow injection; interference masking; flame atomic absorption spectrometry; tap water analysis

The determination of lead in drinking water is becoming increasingly important. The current maximum permissible level in drinking water before entering the distribution network is 50 p.p.b. ${ }^{1}$ Normal flame atomic absorption spectrometry (FAAS), with detection limits greater than 10 p.p.b., does not provide sufficient sensitivity for the determination of lead at this level. Currently electrothermal atomic absorption spectrometry (ETAAS) is the preferred method of analysis ${ }^{2}$ but it is not simple to use. The interfacing of flow injection manifolds to FAAS instruments is convenient and simple, ${ }^{3}$ and enhances the capability of the flame technique. Numerous examples of flow injection pre-concentration techniques have been described,$^{4-8}$ some of which have detection limits equal to those obtained by ETAAS. Although these methods enable very low levels of determinand to be measured, very little work has been undertaken on the effects of possible interferents. In a previous paper ${ }^{9}$ it was shown that the pre-concentration of lead from dilute solutions, using a simple manifold incorporating a small column of immobilised chelating agent, was possible and a detection limit of 1.3 p.p.b. was achieved. The procedure was shown to suffer from interference from other transition metal ions such as iron(III) and copper(II) which can be adsorbed on the column. Other potential interferents, such as calcium, were found not to have a large effect at moderate concentrations. If these pre-concentration methods are to be reliable in the presence of trace amounts of interferents, or capable of being used in the presence of larger amounts of interferents, methods for overcoming the effects of species that compete for the active sites on the stationary phase must be studied. Masking of interferent species in solution has been used extensively for many chemical reactions, especially in complexometric titrations. ${ }^{10}$

In this paper, the effects of interferent species are demonstrated. The development and use of a buffer solution, containing suitable masking agents for the suppression of

* Presented at SAC 89, the 8th SAC International Conference on Analytical Chemistry, Cambridge, UK, 30 July-5 August, 1989.

$\dagger$ Present address: Department of Chemistry, Lederle Graduate Research Tower A, University of Massachusetts, Amherst, MA 01003, USA. some interferences, and its use in determining lead in tap water, as a model system, are described.

\section{Experimental}

\section{Apparatus}

A manifold (Fig. 1) containing Tefzel tubing (Omnifit, Cambridge, UK) with an i.d. of $0.5 \mathrm{~mm}$ based on a prototype pre-concentration unit (PS Analytical, Sevenoaks, Kent, UK), which consisted of a double injection valve and three pumps with associated timing circuitry, was constructed. This device allowed pre-concentration for a variable time followed by washing for a variable time before simultaneous injection of acid eluent and column contents. The manifold was connected to a flame atomic absorption spectrometer (Philips, Model SP9, Philips Analytical, Cambridge, UK) optimised for the determination of lead at $283.3 \mathrm{~nm}$ in an air - acetylene flame. Peaks were recorded using a PM 8251 chart recorder (Philips). A pre-concentration time of $134 \mathrm{~s}$ and a wash time of $32 \mathrm{~s}$ were used for all analyses. The column consisted of a

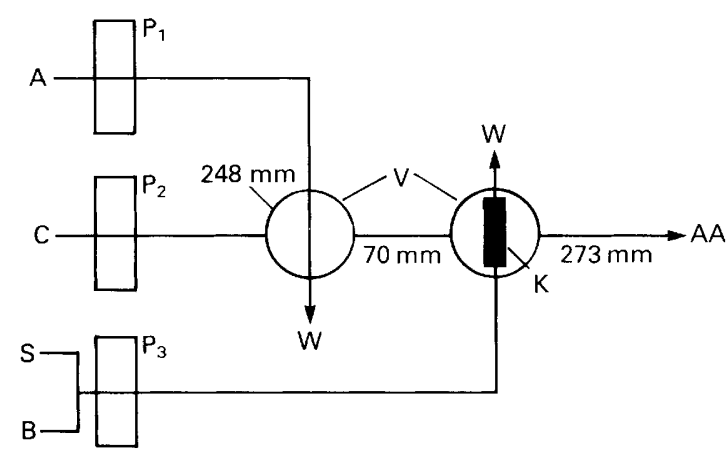

Fig. 1. Pre-concentration manifold. $P_{1}, P_{2}$ and $P_{3}$, Peristaltic pumps; $\mathrm{V}$, double injection valve; $\mathrm{W}$ and $\mathrm{AA}$, connections to the waste and spectrometer, respectively; and $\mathrm{K}$, column connected to the valve by

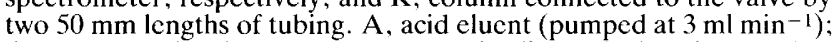
$\mathrm{C}$, water carrier (pumped at $5.5 \mathrm{ml} \mathrm{min-1)} ; \mathrm{B}$, buffer (pumped at $0.8 \mathrm{ml} \mathrm{min}^{-1}$ ); and $\mathrm{S}$, sample (pumped at $5.5 \mathrm{ml} \mathrm{min}^{-1}$ ) 
microbore glass column $50 \times 3 \mathrm{~mm}$ i.d. (Omnifit) fitted with porous poly(vinyl chloride) frits and packed with 8-hydroxyquinoline immobilised on 35-70 mesh silica gel as described previously. ${ }^{9}$ A pH meter (Philips PW 9420) fitted with a glass electrode (Philips Type CE1) was used for $\mathrm{pH}$ determination.

\section{Reagents}

All standards and acids were of SpectrosoL grade $(\mathrm{BDH}$, Poole, Dorset, UK) or AAS grade (Fisons, Loughborough, Leicestershire, UK) and other reagents were either AnalaR $(\mathrm{BDH})$ or AR (Fisons) grade. Water used for dilution was obtained from an $\mathrm{RG}$ reverse osmosis - de-ionisation unit (LiquiPure).

\section{Procedures}

Four solutions each containing 50 p.p.b. of lead were prepared. To three of them were added 10 p.p.m. of either copper, iron or aluminium. Nitric acid was added to give a final concentration of $0.01 \mathrm{~m}$ and a solution of $0.01 \mathrm{~m}$ nitric acid was used as the blank. Each of these solutions was pre-concentrated three times. Six buffers, which consisted of $0.05 \mathrm{~m}$ borax and $0.05 \mathrm{~m}$ borax plus one of the following masking agents $(1 \% \mathrm{~m} / \mathrm{v})$ : sodium fluoride, sodium cyanide, triethanolamine, acetylacetone and thiourea, were investigated. Each buffer was adjusted to $\mathrm{pH} 8$ by the addition of boric acid slurry. Elution was effected with $1.0 \mathrm{~m}$ hydrochloric acid.

After the suitability of each masking agent had been investigated, a buffer consisting of $0.2 \mathrm{~m}$ boric acid, $2 \%$ tri-

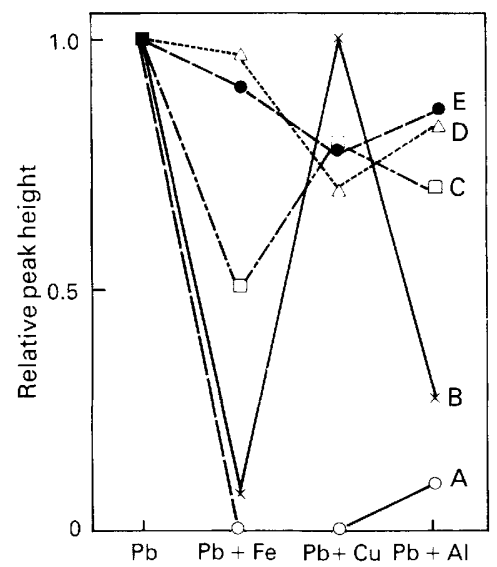

Fig. 2. Relative peak heights compared with a 50 p.p.b. lead standard. Pre-concentration with: A, borax - boric acid buffer; B, borax - boric acid buffer with added cyanide; $C$, borax - boric acid buffer with added thiourea; $D$, borax - boric acid buffer with added triethanolamine; and E, borax - boric acid buffer with added fluoride

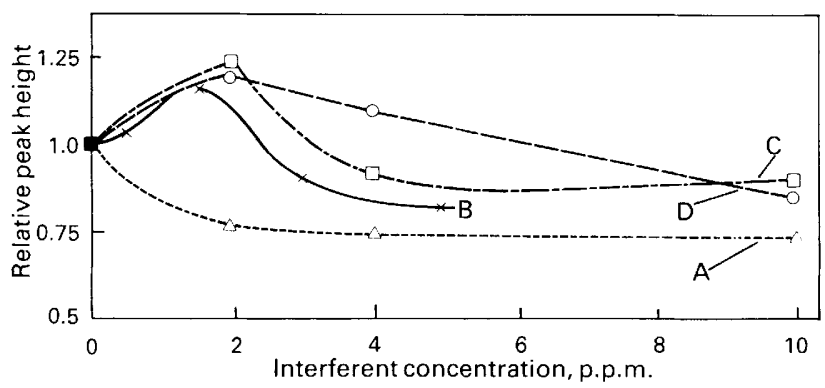

Fig. 3. Effect of increasing interferent concentration on the relative peak heights for pre-concentration of a 50 p.p.b. lead solution using the buffer with masking agents. Added interferents: A, zinc; B, copper; $C$, aluminium; and $D$, iron ethanolamine, $2 \%$ thiourea and $2 \%$ acetylacetone was used for the pre-concentration of samples containing 50 p.p.b. of lead and various concentrations of interferent ions, and in the determination of lead in four spiked tap water samples with calibration against acidified lead standards.

Six tap water samples and four aqueous standards were obtained from the National Rivers Authority Environmental Laboratory (NRAL), Nottingham, UK, in which the lead content had been determined by ETAAS. These samples had been preserved by inclusion of $0.1 \mathrm{~m}$ nitric acid. Six standards including a blank, preserved using $0.1 \mathrm{~m}$ nitric acid, were also supplied to the NRAL by us, and analysed by ETAAS. In order to perform pre-concentration, the molarity of the acid in these samples and standards was reduced from 0.1 to $0.01 \mathrm{~m}$ by the addition of $5 \mathrm{ml}$ of $0.8 \mathrm{M}$ sodium hydroxide solution to $45 \mathrm{ml}$ of sample. All solutions supplied by the NRAL were then analysed using the six standards and an additional standard of 100 p.p.b. treated in the same way. Each pre-concentration was performed in triplicate, whereas four determinations over two batches were performed for each sample analysed by ETAAS. The $\mathrm{pH}$ of each solution was measured before and after addition of sodium hydroxide.

All the solutions analysed, including the blanks, were pre-concentrated in a random order and no carry-over was observed.

\section{Results and Discussion}

The pre-concentration and wash times of 134 and $32 \mathrm{~s}$, respectively, were chosen because these times gave suitable detection limits and were as close as could be achieved to those used previously. ${ }^{9}$ It is recognised that the choice of pre-concentration time is an important parameter in the optimisation of a procedure for dealing with unknown samples. An algorithm for this choice is currently under development ${ }^{11}$ and is based on the concept of extending the conventional calibration range rather than producing a set of discontinuous calibration functions. In order to achieve a calibration the pre-concentration time is chosen such that the upper limit of quantification of the new concentration range corresponds to the lower limit of quantification of the initial range. In turn, this means that the time selected produces a pre-concentration factor equal to the ratio of the upper to lower limits of quantification.

The effect of adding masking agents to the buffer on the interference of different interferent ions is shown in Fig. 2. Clearly, triethanolamine, fluoride and thiourea reduce the interference of all the species investigated, but cyanide is more specific, only having a significant effect on interference by copper ion. Sodium fluoride caused a white precipitate to form in the reagent, sodium cyanide was considered undesirable because of its toxicity and borax $\left(\mathrm{Na}_{2} \mathrm{~B}_{4} \cdot 10 \mathrm{H}_{2} \mathrm{O}\right)$ was found to be unnecessary for adjusting the $\mathrm{pH}$ to 8 . These three compounds were not included in the mixed reagent.

The effect of increasing interferent ion concentration is shown in Fig. 3. There is an apparent increase in the signals when the concentration of each interferent ion is 2 p.p.m. This may be caused by imperfect matching of the acidity of the

Table 1. Recoveries for spiked tap water determined using five lead standards to give a 17 point linear calibration graph, correlation cocfficient 0.9992 . Each sample was analysed by pre-concentration FAAS three times

\begin{tabular}{cccc}
$\begin{array}{c}\text { Nominal } \\
\text { concentration, } \\
\text { p.p.b. }\end{array}$ & $\begin{array}{c}\text { Mean } \\
\text { concentration } \\
\text { found,p.p.b. }\end{array}$ & $\begin{array}{c}\text { Confidence } \\
\text { interval } \\
(95 \%)\end{array}$ & $\begin{array}{c}\text { Recovery, } \\
\%\end{array}$ \\
26.0 & 28.0 & 0 & 107.7 \\
42.0 & 40.4 & 5.7 & 96.2 \\
89.0 & 84.5 & 6.2 & 94.9 \\
65.0 & 64.2 & 3.0 & 98.8 \\
\hline
\end{tabular}




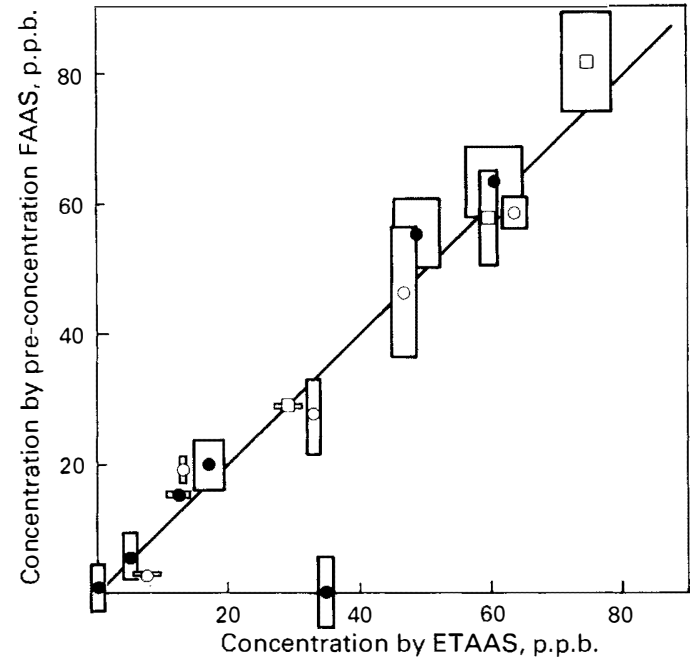

Fig. 4. Regression line of the results of ETAAS and pre-concentration FAAS of tap water samples and aqucous standards. $\bigcirc$. Solutions used as standards for pre-concentration and analysed by ETAAS and pre-concentration FAAS; $\square$, solutions used as standards for ETAAS and analysed by ETAAS and pre-concentration FAAS and 0 . tap water samples. Rectangles about the points represent $95 \%$ confidence intervals for each method

samples. In all instances, the extent of the interference is less than that obtained when using a buffer without masking agents (Fig. 2).

The recoveries for the spiked tap water samples are given in Table 1. Even when non-matrix matched standards were used only one result showed bias at the $95 \%$ confidence level.

The 100 p.p.b. standard gave a peak absorbance of 0.351 , indicating that there is some scope for increasing the preconcentration time. The results for the analysis of tap water samples by pre-concentration FAAS and by ETAAS are presented as a regression line, Fig. 4. Clearly one sample has not been pre-concentrated and it was found that even after addition of sodium hydroxide, the $\mathrm{pH}$ was 1.45 . The $\mathrm{pH}$ of all the other solutions after addition of sodium hydroxide was approximately 2.0. Apparently, if the $\mathrm{pH}$ is 1.45 there is insufficient buffer capacity in the reagent - sample mixture entering the column to bring the $\mathrm{pH}$ to the desired level. The imprecision of the results obtained by pre-concentration FAAS is reflected in the calibration obtained with a detection limit of 6.8 p.p.b. This imprecision is due to the type of pump used for pumping the reagent - buffer mixture. Previously, ${ }^{9}$ a detection limit of 1.3 p.p.b. was obtained by using a microprocessor controlled, stepper-motor driven pump. The type of pumps used in the prototype device possess considerable momentum during pumping and consistent roller pressure is difficult to maintain, causing imprecision in timing and flow-rate, respectively. However, the precision for three results is better than that obtained for ETAAS. Concentration values of 0.025 p.p.b. for the blank generated by our laboratory, with a $95 \%$ confidence interval of $0 \%$, and -0.052 p.p.b. for the blank generated by the NRAL, with a $95 \%$ confidence interval of $0.894 \%$, were obtained. When the regression line was calculated by least squares, and excluding the outlier in order that ETAAS and pre-concentration FAAS can be compared, a slope of 1.02 , an intercept of -0.20 and a correlation coefficient of 0.9902 were obtained, with $95 \%$ confidence intervals of 0.10 and 5.72 for slope and intercept, respectively; the slope is not significantly different from 1.0 and the intercept is not significantly different from 0 .

\section{Conclusion}

An increase in selectivity of immobilised 8-hydroxyquinoline, for the pre-concentration of lead, by the addition of masking agents to the buffer has been demonstrated. With this system interferent ions with concentrations up to 200 -fold in excess of that of lead could be tolerated but the resulting signals were reduced by $25 \%$ compared with those obtained in the absence of interferent species. Sample throughput is not high, but all sample pre-treatment can be carried out on-line if the samples are at the correct $\mathrm{pH}$. Adjustment of $\mathrm{pH}$ can also be incorporated into the system.

The analysis of tap water samples by pre-concentration FAAS was accurate but the precision was not as good as that obtained for ETAAS. The precision and sensitivity can be improved by careful control of sample flow-rate using pumps with precise pumping characteristics and by increasing the sampling time.

It has been shown that column techniques of pre-concentration can suffer from interference by competing species, and that this can be reduced using appropriate masking agents. Although a flame spectrometer was used for detection in this instance, use of the correct interface can allow the application of flow injection techniques to other detectors such as electrothermal spectrometers themselves. This gives rise to the possibility of determining lead at the parts per trillion level.

The authors thank the SERC for financial support for S.R.B., and P. B. Smith of the National Rivers Authority Environmental Laboratory, Nottingham, for provision of samples and analyses by ETAAS.

\section{References}

1. "EC Directive Relating to the Quality of Water Intended for Human Consumption," 80/778/EEC, Off. J. Eur. Commun. July 1980; OJL 229, 30th August, 1980.

2. Smith, P. B., personal communication.

3. Tyson, J. F., Adecyinwo, C. E., Appleton, J. M. H., Bysouth, S. R., Idris, A. B., and Sarkissian, L. L., Analyst, 1985, 110. 487.

4. Malamas, F., Bengtsson, M., and Johansson, G., Anal. Chim. Acta, 1984, 160, 1.

5. Marshall, M. A., and Mottola, H. A., Anal. Chem., 1985, 57. 729.

6. Risinger, L., Anal. Chim. Acta, 1986, 179, 509

7. Olsen, S., Dan. Kemi., 1983, 3, 68.

8. Olsen, S., Pessenda, L. C. R., Rưžička, J., and Hansen, E. H. Analyst, 1983, 108, 905

9. Bysouth, S. R., Tyson, J. F., and Stockwell, P. B., Anal. Chim. Acta, 1988, 214, 329.

10. Perrin, D. D., "Masking and Demasking of Chemical Reactions," Wiley-Interscience, London, 1970.

11. Bysouth, S. R., and Tyson, J. F., unpublished work.

Paper $9 / 03928 G$

Received September 14th, 1989 Accepted January 2nd, 1990 